\title{
Mesenchymal stem cells promote chemoresistance by activating autophagy in intrahepatic cholangiocarcinoma
}

\author{
LINHE GAN $^{1,2^{*}}$, HAO SHEN $^{1,3^{*}}$, XINDUO LI $^{4 *}$, ZHIPENG HAN $^{5}$, YINGYING JING ${ }^{5}$, \\ $\mathrm{XUE} \mathrm{YANG}^{5}$, MENGCHAO WU $^{1}$ and YONG XIA ${ }^{1}$
}

\author{
${ }^{1}$ Department of Hepatic Surgery IV, Shanghai Eastern Hepatobiliary Surgery Hospital, Shanghai 200438; \\ ${ }^{2}$ The Graduate School of Fujian Medical University, Fuzhou, Fujian 350108; ${ }^{3}$ National Center for Liver Cancer, \\ Shanghai 201805; ${ }^{4}$ Shanghai Dazhong Gas Company Health Center, Shanghai 200000; ${ }^{5}$ Tumor Immunology \\ and Gene Therapy Center, Shanghai Eastern Hepatobiliary Surgery Hospital, Shanghai 200438, P.R. China
}

Received February 17, 2020; Accepted October 2, 2020

DOI: $10.3892 / o r .2020 .7838$

\begin{abstract}
Intrahepatic cholangiocarcinoma (ICC) is a type of cancer that is difficult to cure; chemoresistance of cholangiocarcinoma cells affect the prognosis of patients who cannot be treated with surgery. The mechanism underlying this chemoresistance remains unknown. Mesenchymal stem cells (MSCs) are known to be important components of the tumor microenvironment. In the present study, a large number of MSCs were observed to infiltrate the tumor sites of ICC; thus, MSCs were isolated from ICC tumor tissues. It was revealed that herpesvirus entry mediator (HVEM) was overexpressed in ICC-MSCs. The present study then investigated the role of HVEM-overexpressing MSCs in the chemoresistance of cholangiocarcinoma cells. It was demonstrated that HVEM-overexpressing MSCs could support cell survival of chemotherapeutic cholangiocarcinoma cells and inhibited their apoptosis. Further investigations revealed that HVEM-overexpressing MSCs could secrete IL-6 and also activated AMPK/mTOR-dependent autophagy of cholangiocarcinoma cells. Thus, it was concluded that ICC-MSC-induced autophagy is the primary cause of chemoresistance in ICC.
\end{abstract}

\section{Introduction}

Intrahepatic cholangiocarcinoma (ICC) is the second most common type of primary liver cancer. The incidence of ICC accounts for $10-15 \%$ of primary liver cancer $(1,2)$. Data from the WHO database indicated the global morbidity and mortality rates of ICC have demonstrated a clear upward

Correspondence to: Dr Yong Xia, Department of Hepatic Surgery IV, Shanghai Eastern Hepatobiliary Surgery Hospital, The Second Military Medical University, 225 Changhai Road, Shanghai 200438, P.R. China E-mail: xia.yong@126.com

${ }^{*}$ Contributed equally

Key words: intrahepatic cholangiocarcinoma, mesenchymal stem cells, herpesvirus entry mediator, chemoresistance, interleukin 6 trend in recent years (2). Globally, morbidity rates increased from approximately $0.14-1.47$ per 100,000 people in 1993 to $0.29-2.19$ per 100,000 people in 2012 (3). Mortality rates were consistently below $1 / 100,000$ people before 2000 , and in the 2010-2014 period, the mortality rates were between 2-3/100,000 people in most countries (4). Compared with hepatocellular carcinoma (HCC), ICC is more difficult to treat. Surgical resection is currently the main treatment option for ICC, but a considerable number of patients are unable to receive surgery due to the cancer having progressed to the middle and late stages at the time of diagnosis. For patients, conservative treatment based on radiotherapy and chemotherapy is the main treatment method (5-7). In recent years, chemotherapy-based comprehensive treatment has become key to improve the overall efficacy of ICC. Chemotherapy resistance of ICC cells has become a bottleneck restricting the therapeutic effect of ICC (8). Therefore, an in-depth study of the causes and mechanisms underlying ICC chemotherapy resistance is important for cancer research.

Previously, research on tumor chemotherapy resistance has focused on the role of the tumor cell multi-drug resistance gene, protein kinase $\mathrm{C}, \mathrm{ABC}$ membrane transporter and deacetylase in tumor cell chemotherapy resistance (9-11). In recent years, more studies have confirmed the role that the tumor microenvironment plays in chemotherapy-resistance of tumors $(12,13)$.

The tumor microenvironment mainly includes immune and inflammatory cells, interstitial cells and a large number of cytokines, chemokines and matrix-degrading enzymes produced around the tumor (14). Mesenchymal stem cells (MSCs) are important components of the tumor microenvironment and can specifically migrate to primary tumors and metastatic tumors, and proliferate and differentiate into components of the tumor stroma $(15,16)$. There are numerous studies that have demonstrated that MSCs play an important role in chemoresistance in various types of cancer, including gastric cancer, ovarian cancer and leukemia (17-19). Our previous study revealed that MSCs treated with a combination of inflammatory factors TNF- $\alpha$ and IFN- $\gamma$ significantly increased the chemoresistance of liver cancer cells (20). In subsequent studies, it was revealed that there was also a large 
number of MSCs infiltrating in $\operatorname{ICC}(21,22)$. To the best of our knowledge, it is currently unknown whether MSCs in the inflammatory microenvironment of ICC can affect the chemotherapy resistance of cholangiocarcinoma cells. Therefore, the present study investigated whether MSCs in the tumor microenvironment affect chemoresistance of ICC, as well as the underlying mechanism.

\section{Materials and methods}

Ethics statement. The present study was approved by the Institutional Ethics Committee of the Eastern Hepatobiliary Surgery Hospital in Shanghai, China, and was performed in compliance with the Declaration of Helsinki (1975) and its amendments. Patients whose ICC tumor tissues were used in the present study, provided written informed consent. A total of 80 cases of ICC patients diagnosed by surgery at the Eastern Hepatobiliary Surgery Hospital between January 2012 and January 2013 were enrolled. Their tumor tissues and clinical information were collected for data analysis.

Cell culture. The UC-MSCs were purchased from Cyagen Biotechnology Co., Ltd. (cat. no. HUXUC-03011-440). MSCs were cultured in Dulbecco's modified Eagle's medium (DMEM) nutrient mix F12 (cat. no. 10565018; Thermo Fisher Scientific, Inc.) with $10 \%$ fetal bovine serum (FBS; cat. no. 16140071; Gibco $^{\mathrm{TM}}$; Thermo Fisher Scientific, Inc.). ICC cell line RBE (cat.no. TCHu179; Cell Bank of Chinese Academy of Sciences) was cultured in RPMI-1640 medium (item no. 31800; Solarbio Life Sciences) containing 10\% FBS and ICC cell line QBC939 (Tongpai Biotechnology Co., Ltd.) was cultured in DMEM containing $10 \%$ FBS. All cells were cultured at $37^{\circ} \mathrm{C}$ in a humidified atmosphere containing $5 \% \mathrm{CO}_{2}$.

Reagents.Herpesvirus entry mediator(HVEM)-overexpressing adenovirus was synthesized by Obio Technology Corporation (http://www.obiosh.cn/). Enhanced Green Fluorescent Protein (EGFP)-overexpressing adenovirus (OBiO Technology Corp., Ltd.) was used as the control. IL-6 cytokine (cat. no. 206-IL-010/CF) was purchased from R\&D Systems, Inc. Chloroquine (CQ) was purchased from Sigma-Aldrich; Merck KGaA. In order to determine whether autophagy was involved in IL-6-induced chemoresistance in cholangiocarcinoma cells, the inhibitor of autophagy CQ was added to the medium of cholangiocarcinoma cells at a concentration of $10 \mu \mathrm{M}$. Compound $\mathrm{C}$ was purchased from Selleck Chemicals. To determine the role of the AMPK pathway in IL-6-induced autophagy, the AMPK inhibitor, compound $\mathrm{C}$, was used to suppress AMPK signaling at a concentration of $5 \mu \mathrm{M}$.

Isolation of MSCs from tissues of patients with ICC by flow cytometry. ICC tissues were minced and digested at $37^{\circ} \mathrm{C}$ with $2.5 \mathrm{mg} / \mathrm{ml}$ collagenase IV (Sigma Aldrich; Merck KGaA) and $0.1 \mathrm{mg} / \mathrm{ml}$ DNase (Sigma Aldrich; Merck KGaA). Digestion was performed for $30 \mathrm{~min}-1 \mathrm{~h}$ and stopped once no pieces of tissue were left. Then, the suspension was filtered through a $100-\mu \mathrm{m}$ nylon cell strainer and spun $5 \mathrm{~min}$ at $300-400 \mathrm{x}$ g, at $4^{\circ} \mathrm{C}$ to obtain single-cell suspension. The suspension was then incubated with FITC-conjugated SSEA-4 (cat. no. 330409; BioLegend, lnc.) for $30 \mathrm{~min}$ at $4^{\circ} \mathrm{C}$. Cells were washed 3 times with PBS, and then FITC-positive cells were assessed via flow cytometry. Flow cytometry was carried out with $\mathrm{MoFlo}^{\mathrm{TM}} \mathrm{XDP}$ Cell Sorter (Beckman Coulter, Inc.) and the data analysis was performed using FlowJo software v.7.6.5 (BD Biosciences).

Apoptosis detection by flow cytometry. RBE human cholangiocarcinoma cells $\left(1 \times 10^{6}\right)$ and QBC939 human cholangiocarcinoma cells $\left(1 \times 10^{6}\right)$ were plated into 6 -well plates, $50 \%$ conditioned medium of control MSCs and HVEM-overexpressing MSCs were added. In addition, chemotherapeutic drugs, 5-FU (25 $\mu \mathrm{g} / \mathrm{ml})$ (cat. no. HY-90006; MedChemExpress) and cisplatin (5 $\mu \mathrm{g} / \mathrm{ml})$ (cat. no. HY-17394; MedChemExpress) were added to the culture system for 48 h. Cells were stained by Annexin V Alexa Fluor 647 (cat. no. R37175; Invitrogen; Thermo Fisher Scientific, Inc.) and propidium iodide (PI; cat. no. P3566; Invitrogen; Thermo Fisher Scientific, Inc.) at $4^{\circ} \mathrm{C}$ for $30 \mathrm{~min}$, and then the cells were washed with PBS. Annexin V-and PI-positive cells were analyzed by flow cytometry. Flow cytometry was carried out with MoFlo ${ }^{\mathrm{TM}}$ XDP Cell Sorter and the data analysis was performed using FlowJo software v.7.6.5.

Chemoresistance experiment. RBE human cholangiocarcinoma cells $\left(1 \times 10^{6}\right)$ were plated into 6 -well plates, and treated with various IL- 6 concentrations $(0.1,1,5,10,20$ and $50 \mathrm{ng} / \mathrm{ml})$ for 6-8 $\mathrm{h}$. Then, chemotherapeutic drugs, 5-FU $(25 \mu \mathrm{g} / \mathrm{ml})$ and cisplatin $(5 \mu \mathrm{g} / \mathrm{ml})$ were added to the culture system for $48 \mathrm{~h}$. Western blotting was used to detect the level of autophagy, and CCK-8 and apoptosis assays were employed to examine cell viability and cell death. The lowest concentration of IL-6 (10 ng/ml) which could effectively promote autophagy and chemoresistance was used for subsequent experiments.

Cell Counting Kit-8 (CCK-8) assay. Cholangiocarcinoma cells (3,000 cells/well) were plated into 96-well plates, and 50\% conditioned medium of control MSCs and HVEM-overexpressing MSCs were added. In addition, chemotherapeutic drugs, 5 -FU and cisplatin were added to the culture system at $25 \mu \mathrm{g} / \mathrm{ml}$ and $5 \mu \mathrm{g} / \mathrm{ml}$, respectively. After $48 \mathrm{~h}$, a CCK-8 assay (cat. no. ab228554; Abcam) was used to assess the cell viability. CCK-8 reagent was added into each well at a ratio of 1:10 with medium. After incubation for $1 \mathrm{~h}$ at $37^{\circ} \mathrm{C}$, the absorbance was detected using a microplate reader at a wavelength of $450 \mathrm{~nm}$.

Gene overexpression mediated by recombinant adenovirus. A recombinant adenovirus of HVEM overexpression was purchased from Genechem Biotech, Inc. This adenovirus was amplified directly from the original adenovirus strain. The original adenovirus strain was constructed by co-transfecting plasmid and packaging plasmid to adenovirus. The plasmid vector was pADV-mCMV-HA-P2A and pADV-mCMV-HA-P2A-EGFP was used as a control. Plasmid $(1 \mu \mathrm{g} / \mu \mathrm{l})$ was transfected with Lipofectamine 3000 transfection reagent (cat. no. L3000015; Invitrogen; Thermo Fisher Scientific, Inc.) into the adenovirus at $37^{\circ} \mathrm{C}$ for 24 h. 293 cells (1x106 ; cat. no. GNHu18; Cell Bank of Chinese Academy of Sciences) were transfected to amplify the adenovirus. Adenovirus particles were collected and the concentration was detected. MSCs were transfected by this adenovirus at MOI 20 for $12 \mathrm{~h}$ with serum-free medium. Then, $48 \mathrm{~h}$ later, HVEM expression was verified by western blotting. 
Western blotting. Total protein was extracted from cells using RIPA buffer (Beyotime Institute of Biotechnology), and the protein concentration was detected using a BCA assay. A total of $20 \mu \mathrm{g}$ protein per lane was separated via $12 \%$ SDS-PAGE (Zhao Rui Biotech Co., Ltd.). The proteins were then transferred onto nitrocellulose membranes. Next, $5 \%$ non-fat milk was used to block non-specific sites for $2 \mathrm{~h}$ at room temperature. The membranes were incubated with primary antibodies against: HVEM (product code ab47677; Abcam),LC-3 (product no. 12741), p62 (product no. 88588) and GAPDH (product no. 5174) (all 1:1,000; from Cell Signaling Technology, Inc) at $4^{\circ} \mathrm{C}$ overnight. The membranes were then washed with TBST $[\mathrm{TBS}+0.1 \%(\mathrm{v} / \mathrm{v})$ Tween-20) 3 times, and then incubated with corresponding secondary antibodies goat anti-rabbit or goat anti-mouse IgG H\&L (HRP) (cat. nos. ab205718 or ab205719, respectively; 1:5,000; Abcam) at room temperature for $2 \mathrm{~h}$ and washed with TBST another 3 times. ECL (Cell Signaling Technology, Inc.) was used for visualization.

Reverse transcription-quantitative $(R T-q) P C R$. Total RNA was extracted from cells using TRIzol ${ }^{\circledR}$ (cat. no. 15596-026; Invitrogen; Thermo Fisher Scientific, Inc.) and reverse-transcribed into cDNA using a Bestar qPCR RT kit (cat. no. DBI-2220; Shanghai Xinghan Sci\&Tech Co., Ltd.) according to the manufacturer's protocol. The PCR cycle was performed according to manufacturer's instructions with initial denaturation at $37^{\circ} \mathrm{C}$ for $15 \mathrm{~min}, 95^{\circ} \mathrm{C}$ for $2 \mathrm{~min}$ followed by 11 cycles at $95^{\circ} \mathrm{C}$ for $30 \mathrm{sec}, 65^{\circ} \mathrm{C}$ for $30 \mathrm{sec}$ and $72^{\circ} \mathrm{C}$ for $1 \mathrm{~min}$ and a final extension at $72^{\circ} \mathrm{C}$ for $5 \mathrm{~min}$. mRNA expression of HVEM was detected by RT-PCR using a Bestar real-time SYBR Green PCR master mix (DBI-2043; Shanghai Xinghan Sci\&Tech Co., Ltd.) with an ABI PRISM 7300 system. GAPDH was used as the internal control and data analysis was performed using the $2^{-\Delta \Delta \mathrm{Cq}}$ method (23). The primers used were as follows: HVEM forward, 5'-TCATCGTCATTGTTTGCTCCA-3' and reverse, 5'-ACCTTGACTACATCACCCCTT-3'; GAPDH forward, 5'-GGAGCGAGATCCC TCCAAAAT-3' and reverse, 5'-GGCTGTTGTCATACTTCTCATGG-3'.

Bioplex assay. Conditioned medium of control MSCs and HVEM-MSCs were collected following culture with serum-free medium for $24 \mathrm{~h}$. Cytokines in the medium were detected by a Bio-Plex Pro ${ }^{\mathrm{TM}}$ Human Cytokine 27-plex assay (cat. no. M500KCAF0Y). Briefly, serially diluted standards and undiluted conditioned media $(50 \mu \mathrm{l})$ were added to a microfilter plate containing antibody-coupled beads for each of the 27 analytes and incubated for $60 \mathrm{~min}$ with continuous shaking at room temperature between $20^{\circ} \mathrm{C}$ and $30^{\circ} \mathrm{C}$. After washing, the biotinylated detection antibodies were added for 30 min with shaking. The microfilter plate was washed again, and Streptavidin-PE (50 $\mu \mathrm{l})$ was added and incubation continued at room temperature with shaking $(90 \mathrm{x} \mathrm{g}$ for $1 \mathrm{~min}$ followed by $10 \mathrm{x} \mathrm{g}$ for $15 \mathrm{~min})$. Assay buffer $(125 \mu \mathrm{l})$ was added to each well of the microfilter plate before being read on a Bio-Plex 200 machine (Bio-Rad Laboratories, Inc.).

Immunohistochemical and immunofluorescence staining. Patient tissues were fixed with $10 \%$ formalin at room temperature for $24 \mathrm{~h}$, embedded in paraffin, and sliced into 5- $\mu \mathrm{m}$ thick sections for the immunohistochemistry assay. Sections were de-paraffinised with xylene and rehydrated with three successive changes in ethanol, and $1 \%$ bovine serum albumin (Gibco; Thermo Fisher Scientific, Inc.) was used to block non-specific sites at $37^{\circ} \mathrm{C}$ for $30 \mathrm{~min}$. The sections were then incubated with primary antibodies against: HVEM (1:100), LC-3 (1:200) and p62 (1:200), at $4^{\circ} \mathrm{C}$ overnight. PBS was used to wash the sections 3 times, and then sections were incubated with corresponding secondary antibodies goat anti-rabbit and goat anti-mouse IgG H\&L (HRP) at $37^{\circ} \mathrm{C}$ for $30 \mathrm{~min}$. After washing with PBS 3 times, DAB (1 mg/ml; cat. no. D8417; Sigma-Aldrich; Merck KGaA) was used at room temperature between $20^{\circ} \mathrm{C}$ and $30^{\circ} \mathrm{C}$ for $3 \mathrm{~min}$ for color development. Hematoxylin was used to stain nucleic acid at room temperature. A light field microscope (magnification, $\mathrm{x} 200$ ) was used to observe and quantify positive cells per $\mathrm{mm}^{2}$ (Leica Microsystems, Inc.). We used immunohistochemical scoring standards to define high or low IL-6 levels. The intensity was scored as follows: 0 , negative; 1 , weak; 2 , moderate; and 3 , strong. The frequency of positive cells was defined as follows: $0,<5 \% ; 1,5-25 \% ; 2,26-50 \% ; 3,51-75 \%$; and $4,>75 \%$. The staining index (values, 0-12) was determined by multiplying the score for staining intensity with the score for positive area. For statistical analysis, scores of 0 to 7 were considered low expression and scores of 8 to 12 were considered high expression) (24).

For immunofluorescence staining, the sections were boiled with citrate ( $\mathrm{pH}$ 6.0), permeabilized in PBS supplemented with $0.2 \%$ Triton X-100 (PBST) and blocked with $2 \%$ normal donkey serum (cat. no. ab7475; Abcam) for $1 \mathrm{~h}$ at room temperature. Primary antibodies: HVEM (1:200) and SSEA-4 (1:500; cat. no. ab16287; Abcam, Inc.) were then incubated at $4^{\circ} \mathrm{C}$ overnight. Subsequently, after washing with PBS, the sections were incubated with corresponding secondary antibodies goat anti-rabbit or goat anti-mouse IgG H\&L (Alexa Fluor ${ }^{\circledR} 488$ ) (cat. no. ab150077 or ab150113, respectively; 1:1,000; Abcam), stained with DAPI (5 $\mu \mathrm{g} / \mathrm{ml}$; cat. no. D8417; Sigma-Aldrich; Merck $\mathrm{KGaA}$ ) for $15 \mathrm{~min}$ at room temperature and then embedded using Vectashield ${ }^{\circledR}$ (Vector Laboratories, Inc.). Images were captured on SP8 confocal microscope (magnification, x200) (Leica Microsystems, Inc.).

Statistical analysis. Statistical analyses were performed using the SPSS 20.0 (IBM Corp.). Categorical variables were compared using the $\chi^{2}$ test. Continuous variables were compared using the Mann-Whitney $U$ test as appropriate. Pearson's correlation coefficient was used to determine correlations between continuous normally distributed variables. The overall survival curve was drawn by the Kaplan-Meier method. Log-rank test was used to compare the survival time of patients between each group. Data sets were analyzed by analysis of variance (ANOVA) with a posteriori contrast by least significant difference (for comparisons among multiple groups) or by paired Student's t-test (for comparison between two groups). Immunohistochemical images were analyzed by Image-Pro ${ }^{\circledR}$ Plus 6.0 (IPP; Media Cybernetics, Inc.). Each experiment was performed in triplicate. $\mathrm{P}<0.05$ was considered to indicate a statistically significant difference.

\section{Results}

HVEM is upregulated in MSCs isolated from ICC. At first, immunofluorescence staining of SSEA4 and HVEM was 
A
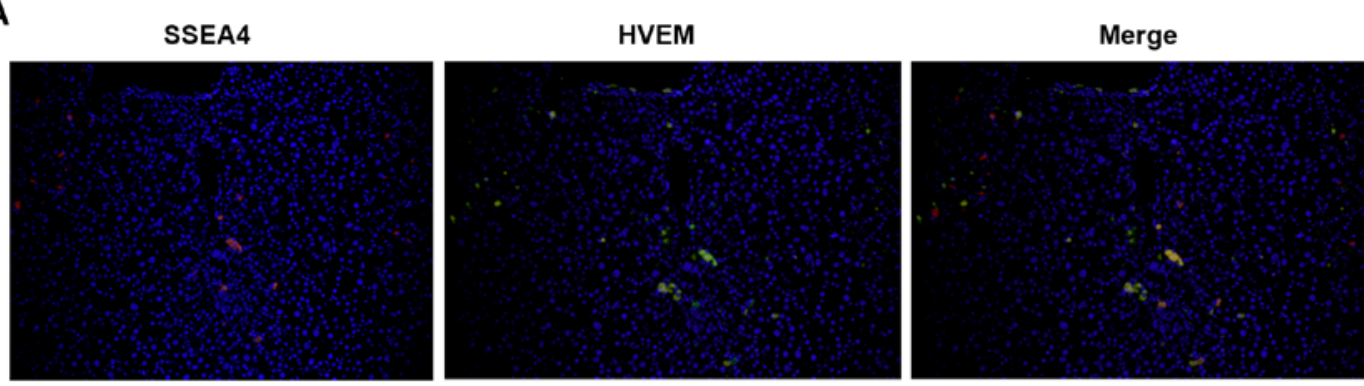

B

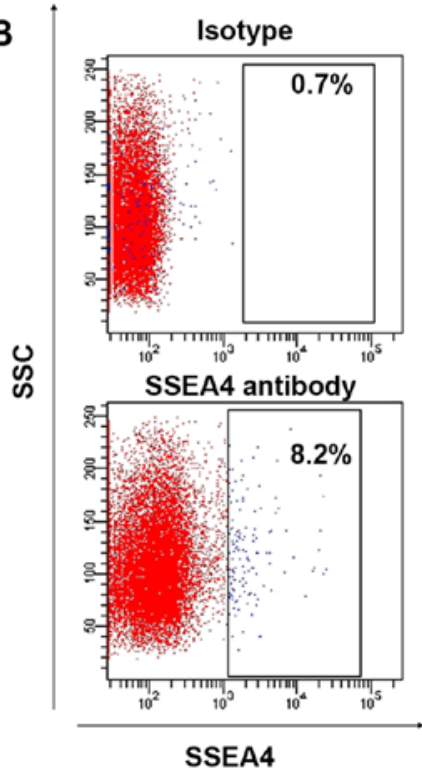

C

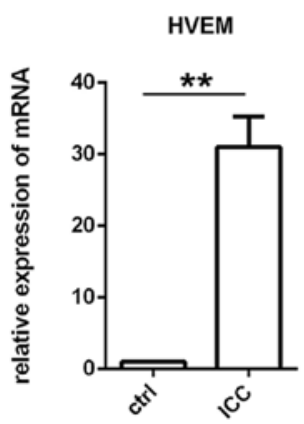

D

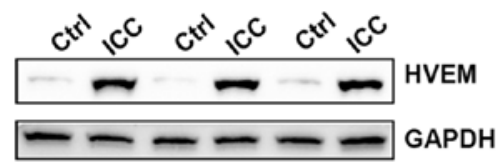

Figure 1. HVEM is overexpressed in MSCs isolated from ICC. (A) The expression of SSEA4 and HVEM was detected in ICC specimens by immunofluorescence staining. (B) Fresh liver specimens were collected from ICC patients and then MSCs were isolated from them by FACS. SSEA4 antibody was used to identify MSCs. (C and D) HVEM was detected in ICC-MSCs by RT-qPCR assay and western blotting assay, respectively. ${ }^{* *}$ P<0.01. HVEM, herpesvirus entry mediator; MSCs, mesenchymal stem cells; ICC, intrahepatic cholangiocarcinoma; RT-qPCR, reverse transcription-quantitative PCR.

performed in the liver specimens from several ICC patients. As revealed in Fig. 1A, the expression of the SSEA4 (red) and the HVEM (green) exhibited high overlap. Then, using the fresh liver specimens collected from the patients with ICC, MSCs were isolated via fluorescence-activated cell sorting (FACS). SSEA4 antibody was used to identify MSCs $(25,26)$. As presented in Fig. 1B, there were $\sim 7.5 \%$ SSEA-positive cells detected. Then, SSEA4-positive cells were collected and HVEM was detected in ICC-MSCs via western blotting and RT-qPCR. Cholangiocarcinoma originates from abnormal cell differentiation caused by chronic inflammation. Thus, there is chronic inflammation in the para-carcinoma tissue. Since the function of MSCs is easily affected by inflammatory factors, MSCs in para-carcinoma tissue cannot be used as a normal control $(27,28)$. Umbilical cord-derived MSCs are derived from normal tissues and are currently the most commonly used MSCs in research and applications (29). Therefore, UC-MSCs were used as a normal control in this study. As presented in Fig. 1D, it was revealed that HVEM expression in ICC-MSCs was significantly higher than that in UC-MSCs. The results of the RT-qPCR demonstrated the same trend (Fig. 1C).

In addition, the level of HVEM between the primary MSCs sorted by FACS and HVEM-overexpressed MSCs by adenovirus were detected by western blotting. As revealed in Fig. S1, there was no significant difference between the expression of HVEM between the primary MSCs sorted by FACS and the HVEM-overexpressed MSCs by adenovirus.

HVEM-overexpressing MSCs promote the capacity of chemoresistance in cholangiocarcinoma cells. Since HVEM was expressed at high levels in MSCs in cholangiocarcinoma, in order to detect the role of HVEM-overexpressed MSCs in the chemoresistance of cholangiocarcinoma, the present study constructed an HVEM-overexpressing adenovirus, transfected with normal MSCs, which were isolated from healthy individuals. As presented in Fig. 2A, the adenovirus effectively induced HVEM expression in MSCs. Then, the supernatant liquid of HVEM-overexpressing MSCs was added to the RBE and QBC939 cell culture medium. The chemotherapeutic drugs, 5-FU and cisplatin (25 and $5 \mu \mathrm{g} / \mathrm{ml}$ ) were added to the culture system for $48 \mathrm{~h}$. A CCK-8 assay was used to examine the cell viability. Compared with the control group, HVEM-overexpressing MSCs demonstrated a significantly higher cell viability (Fig. 2B-E). Consistent with this, the apoptosis assay also demonstrated that HVEM-overexpressing MSCs could significantly enhance the resistance to 
A

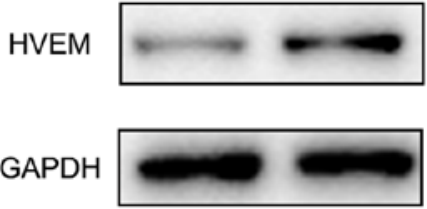

Control Ov-HVEM
B

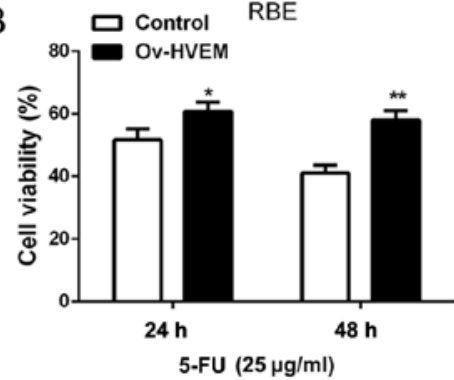

E

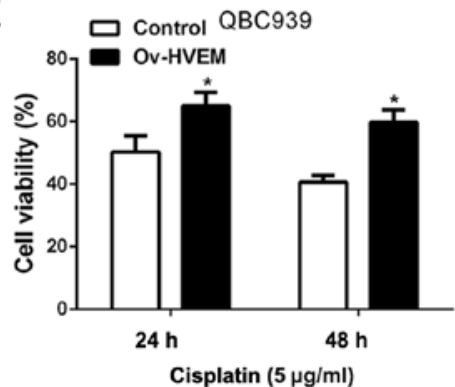

Cisplatin $(5 \mu \mathrm{g} / \mathrm{ml})$

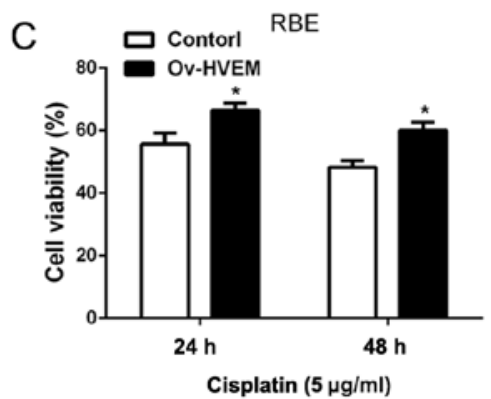

Cisplatin $(5 \mu \mathrm{g} / \mathrm{ml})$
D

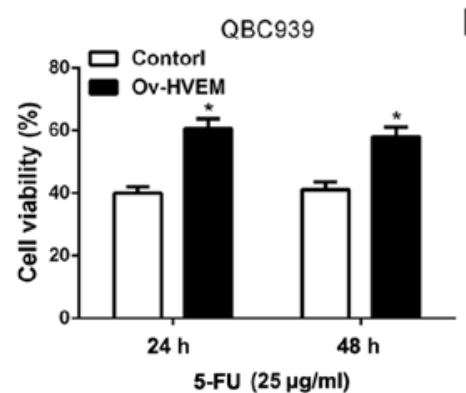

$\mathrm{F}$

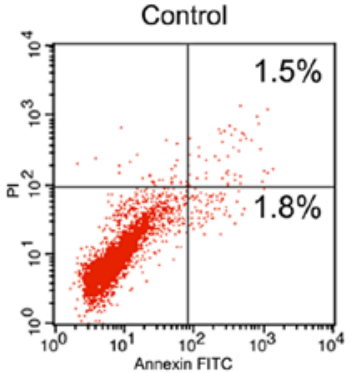

H

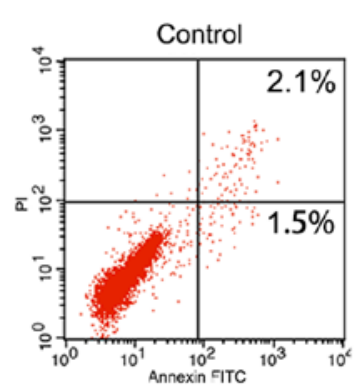

J

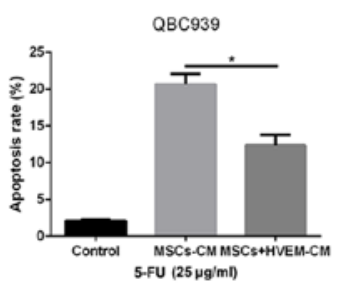

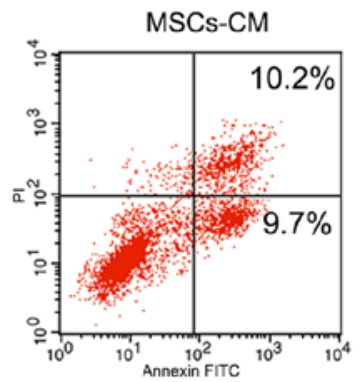
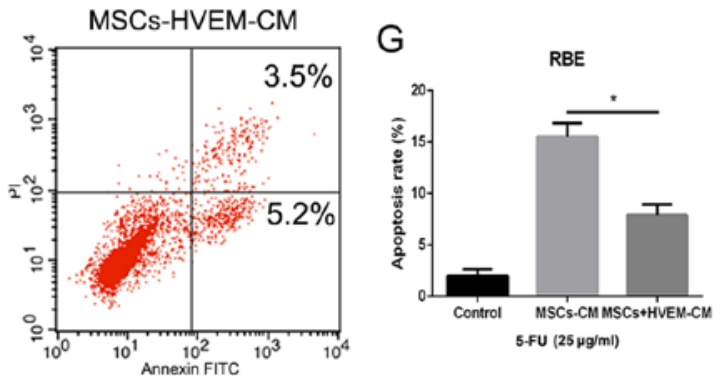

I
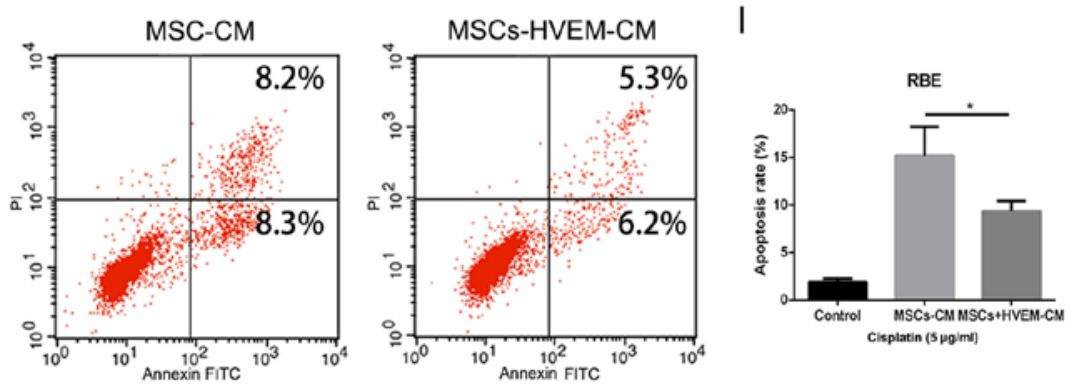

Figure 2. HVEM-overexpressed MSCs promote the capacity of chemoresistance in cholangiocarcinoma cells. (A) HVEM expression was detected by western blotting in MSCs. Ov-HVEM, HVEM overexpression. (B-E) CCK-8 assays were employed to examine the cell viability in RBE and QBC939 cell lines co-cultured with MSCs, and 5-FU and cisplatin were added to the culture system. ${ }^{*} \mathrm{P}<0.05$ and ${ }^{* *} \mathrm{P}<0.01$ compared with the control. (F-K) Cell apoptosis was performed by flow cytometry. Statistical results are presented in G, I-K. " $\mathrm{P}<0.05$. HVEM, herpesvirus entry mediator; MSCs, mesenchymal stem cells; Ov-HVEM, HVEM overexpression; CCK-8, Cell Counting Kit-8; CM, conditioned media.

chemotherapeutic drugs (Fig. 2F-K). The aforementioned data indicated that HVEM-overexpressing MSCs promoted the capacity of chemoresistance in cholangiocarcinoma cells.
HVEM-overexpressing MSCs increase chemoresistance in cholangiocarcinoma cells by secreting $I L-6$. To determine the underlying mechanism by which HVEM-overexpressing 
A

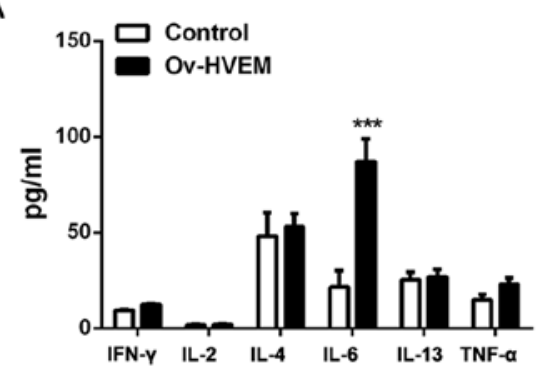

C

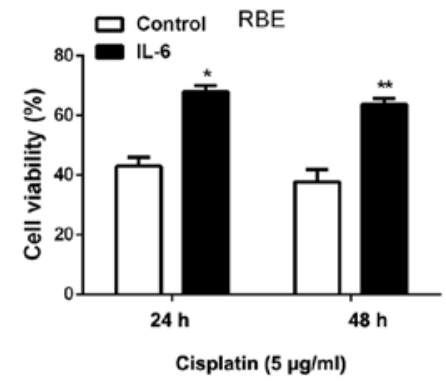

$\mathrm{F}$
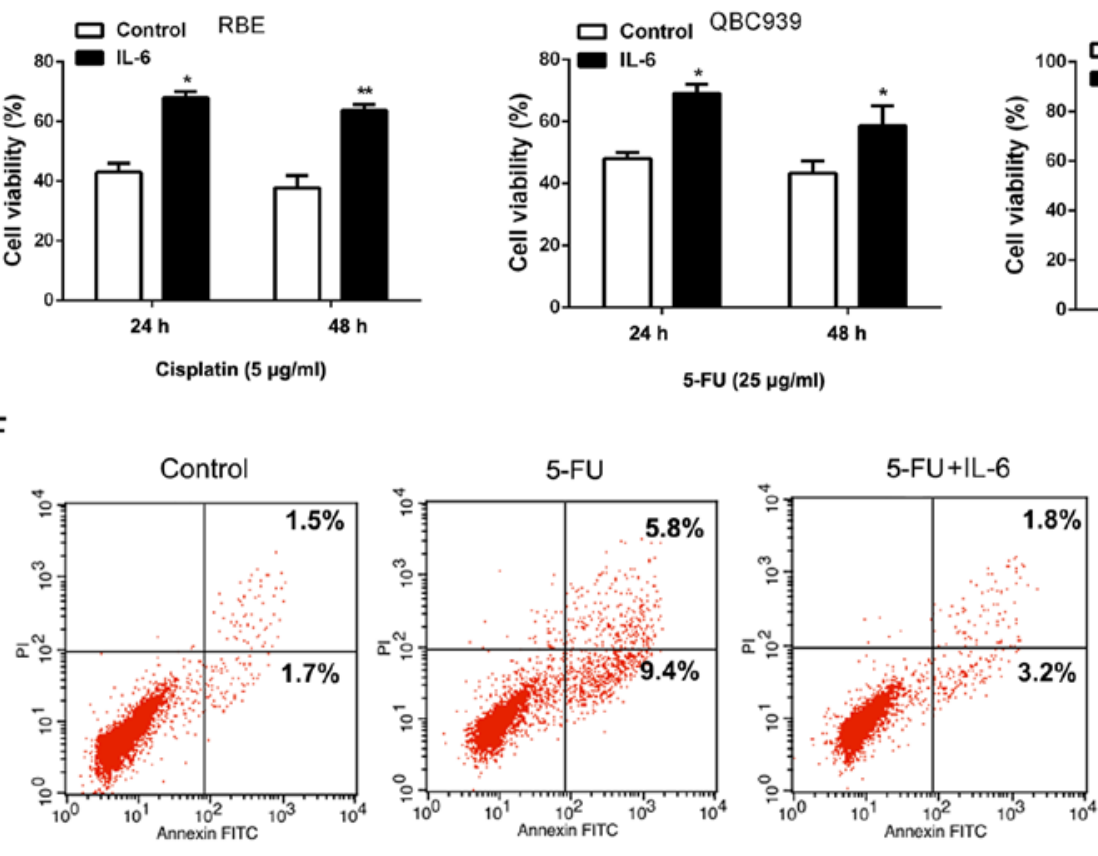

E

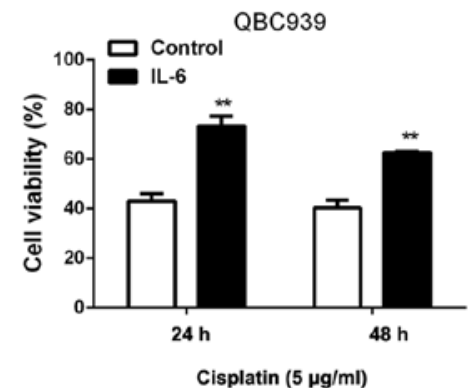

G

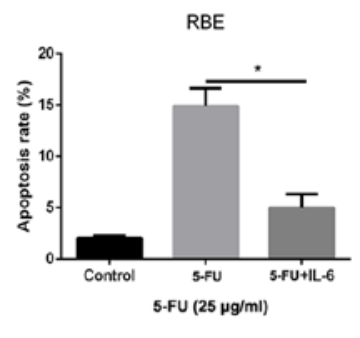

$\mathrm{H}$

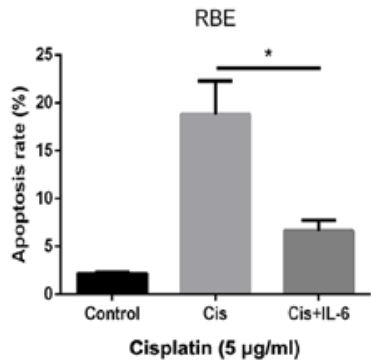

I

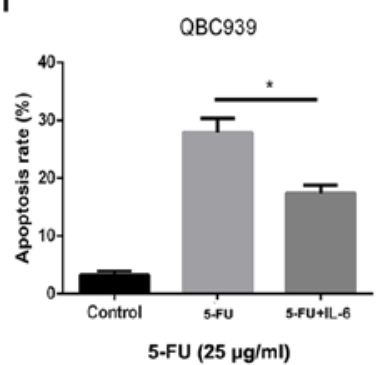

$\mathrm{J}$

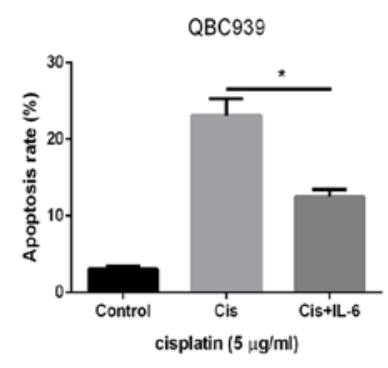

Figure 3. HVEM-overexpressed MSCs increase chemoresistance in cholangiocarcinoma cells by secreting IL-6. (A) Inflammatory factors in MSCs were assessed by bioplex assay. ${ }^{* * *} \mathrm{P}<0.001$ compared with the control. (B-E) CCK-8 assays were employed to examine the cell viability in RBE and QBC939 cell lines treated with IL-6 and 5-FU, and cisplatin. ${ }^{*} \mathrm{P}<0.05$ and ${ }^{* *} \mathrm{P}<0.01$ compared with the control. (F-J) Cell apoptosis was performed by flow cytometry. Statistical results are presented in G-H. *P<0.05. HVEM, herpesvirus entry mediator; MSCs, mesenchymal stem cells; IL-6, interleukin 6; CCK-8, Cell Counting Kit-8; Cis, cisplatin.

MSCs promoted chemoresistance in cholangiocarcinoma cells, a bioplex assay was performed to detect the cytokines in HVEM-overexpressing MSCs. As presented in Fig. 3A, compared with the control group, the HVEM-overexpressing group exhibited a significantly higher level of IL-6 in MSCs. In order to confirm the role of IL-6 in the chemoresistance of cholangiocarcinoma cells, IL-6 was used to treat cholangiocarcinoma cells directly at a concentration of $10 \mathrm{ng} / \mathrm{ml}$. The cell viability and death were detected to evaluate the chemoresistance in cholangiocarcinoma cells. Following treatment with 5-FU and cisplatin, IL-6 increased the cell viability in RBE and QBC939 cell lines (Fig. 3B-E). A decreased amount of 5-FU or cisplatin-induced cell death was observed in IL-6-pretreated cholangiocarcinoma cells (Fig. 3F-J). These results indicated that HVEM-overexpressing MSCs promoted chemoresistance in cholangiocarcinoma cells through IL-6.

IL-6 promotes the chemoresistance of cholangiocarcinoma cells through activation of autophagy. The present study then examined the mechanism underlying IL-6-induced 
A

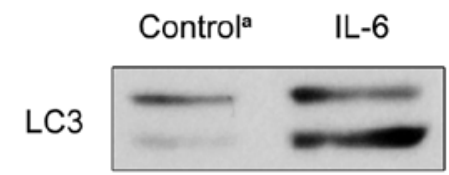

p62

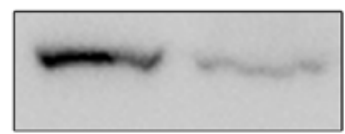

GAPDH

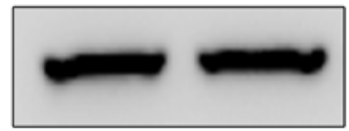

B

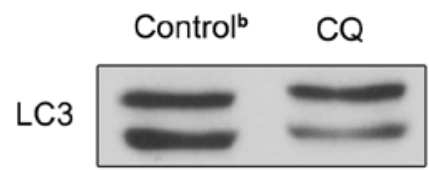

p62

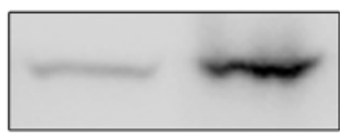

GAPDH

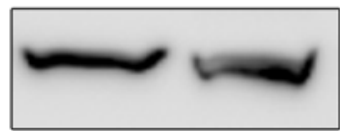

C
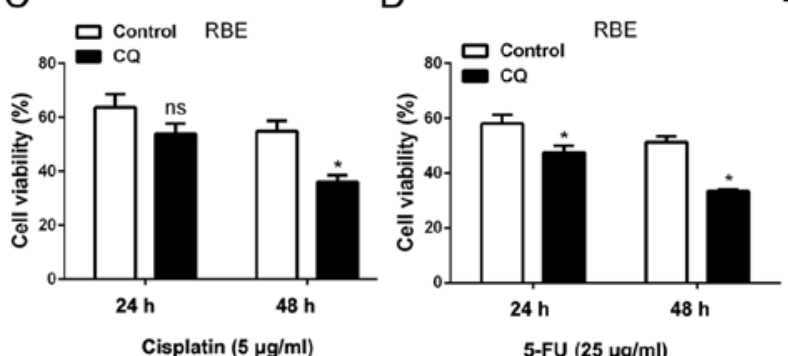

E

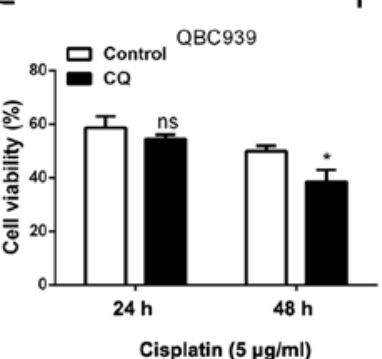

F

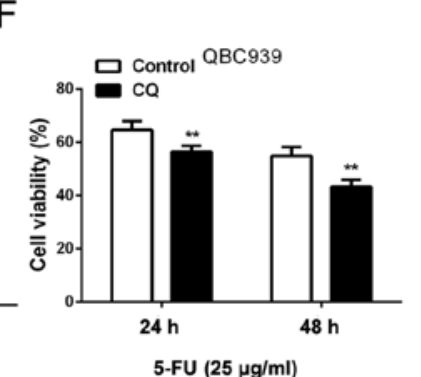

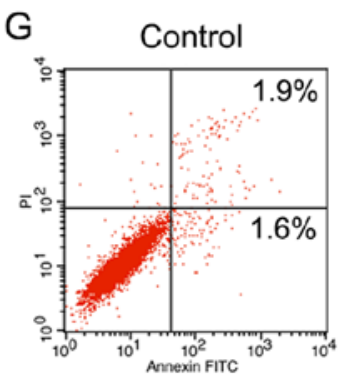

I

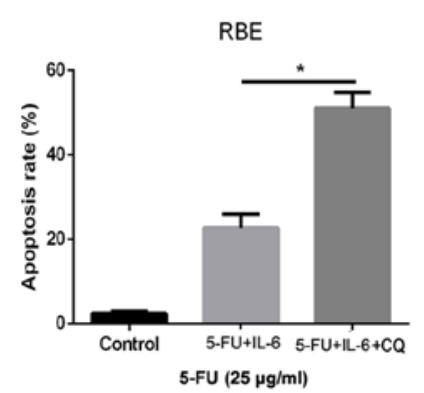

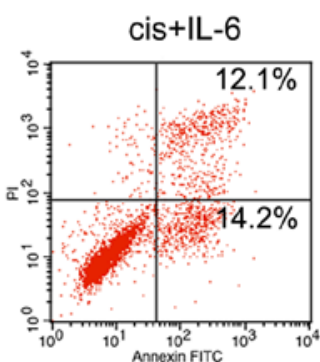

J

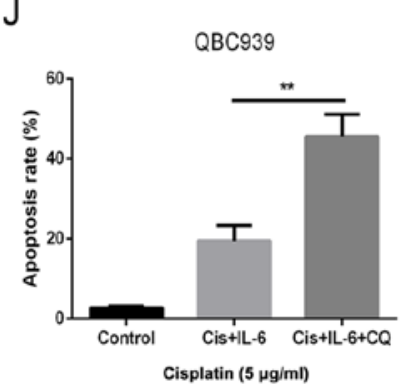

$\mathrm{H}$

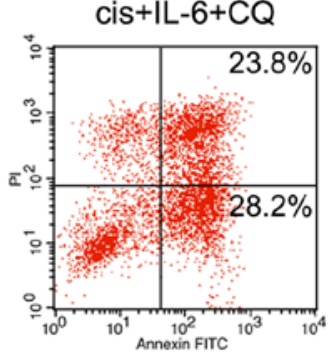

RBE

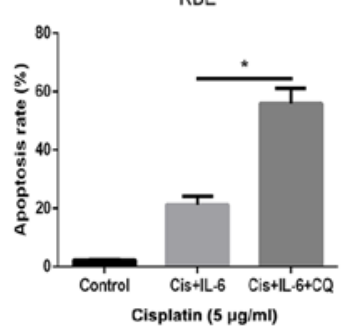

K

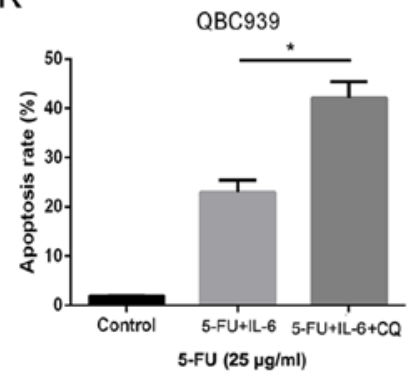

Figure 4. IL-6 promotes the chemoresistance of cholangiocarcinoma cells through activation of autophagy. (A) The expression of LC3 and p62 was detected by western blotting in the RBE cell line with treatment of IL-6. (The Control ${ }^{\mathrm{a}}$ group was the RBE cell line without IL-6 pretreatment). (B) RBE cells were treated with IL-6 and (CQ). Then western blotting was used to examine LC3 and p62 expression. (The Control group was the RBE cell line without IL-6 and CQ pretreatment). (C-F) CCK-8 assays were employed to examine the cell viability in RBE and QBC939 cell lines treated with IL-6, CQ and 5-FU, cisplatin. ${ }^{*} \mathrm{P}<0.05$ and ${ }^{* *} \mathrm{P}<0.01$ compared with the control. (G-K) Cell apoptosis was performed by flow cytometry. Statistical results are presented in $\mathrm{H}-\mathrm{K}$. " $\mathrm{P}<0.05$ and ${ }^{* *} \mathrm{P}<0.01$. IL-6, interleukin 6; CQ, chloroquine; CCK-8, Cell Counting Kit-8; Cis, cisplatin.

chemoresistance in cholangiocarcinoma cells. Autophagy has been reported to play an important role in tumor cell chemosensitivity $(30,31)$. Therefore, the level of autophagy was detected in IL-6-treated RBE cells via western blotting. The results indicated that LC-3 expression was upregulated, whereas p62 expression was downregulated, which are two of the most important markers of autophagy (32) (Fig. 4A). In order to determine whether autophagy was involved in IL-6-induced chemoresistance in cholangiocarcinoma cells, the inhibitor of autophagy CQ was added to the medium of cholangiocarcinoma cells at a concentration of $10 \mu \mathrm{M}$. As revealed in Fig. 4B, CQ could effectively suppress LC3 expression and increase p62 expression in RBE cells. The CCK-8 and apoptosis assays were also employed to examine cell viability and cell death in RBE cells treated with 5-FU and cisplatin. As anticipated, the enhancement of IL-6-induced survival in RBE cells was diminished when autophagy was inhibited by CQ (Fig. 4C-F). Consistent with 
Table I. Baseline characteristics of patients.

\begin{tabular}{|c|c|c|c|}
\hline \multirow[b]{2}{*}{ Variable } & \multicolumn{2}{|c|}{ Number $(\%) /$ median (IQR) } & \multirow[b]{2}{*}{ P-value } \\
\hline & High-expression IL-6 group $(\mathrm{n}=44)$ & Low-expression IL-6 group $(n=36)$ & \\
\hline Age (years) & $53.7(46.5-57.5)$ & $50.6(44.5-55.1)$ & 0.440 \\
\hline $\operatorname{Sex}, \mathrm{n}(\%)$ & & 0.339 & \\
\hline Male & $30.0(68.1)$ & $28.0(77.8)$ & \\
\hline Female & $14.0(31.8)$ & $8.0(22.2)$ & \\
\hline TBIL (mmol/l) & $13.1(10.3,16.3)$ & $16.2(13.6,19.2)$ & 0.179 \\
\hline $\operatorname{ALB}(g / 1)$ & $42.0(40.0,44.9)$ & $42.5(40.3,43.5)$ & 0.446 \\
\hline ALT (IU/l) & $41(25.9,51.8)$ & $37.7(28.6,60.0)$ & 0.969 \\
\hline AST (IU/l) & $35.6(27.0,58.5)$ & $32.8(24.4,41.5)$ & 0.206 \\
\hline $\operatorname{PLT}\left(\times 10^{9} / 1\right)$ & $151.0(119.0-182.0)$ & $143.0(104.5-193.5)$ & 0.670 \\
\hline PT (S) & $12.0(11.3,12.5)$ & $12.0(11.5,12.9)$ & 0.236 \\
\hline $\operatorname{AFP}(\mu \mathrm{g} / 1)$ & $93.5(64.3,115.0)$ & $87.5(58.7,120.3)$ & 0.811 \\
\hline $\mathrm{CEA}(\mu \mathrm{g} / \mathrm{l})$ & $1.6(1.0,2.1)$ & $2.50(1.2,2.6)$ & 0.074 \\
\hline CA19-9 (IU/ml) & $45.6(30.5,73.5 .0)$ & $43.5(32.8,60.3)$ & 0.655 \\
\hline Tumor diameter $(\mathrm{cm})$ & $4.0(3.0,7.0)$ & $4.6(2.4,6.0)$ & 0.721 \\
\hline Tumor number, n (\%) & & 0.604 & \\
\hline Multiple & $10.0(22.7)$ & $10.0(27.8)$ & \\
\hline Solitary & $34.0(77.3)$ & $26.0(72.2)$ & \\
\hline
\end{tabular}

Values of age, TBIL, ALB, ALT, AST, PLT, PT, AFP, CEA, CA19-9 are median (IQR) and analyzed by Mann-Whitney U test. Values of sex and tumor number are patient number and percentage and were analyzed by $\chi^{2}$ test. IL-6, interleukin 6; IQR, interquartile range, TBIL, total bilirubin; ALB, albumin; ALT, alanine aminotransferase; AST, aspartate transaminase; PLT, platelet; PT, prothrombin time; AFP, alpha fetal protein; CEA, carcino-embryonic antigen; CA19-9, carbohydrate antigen 19-9.

A

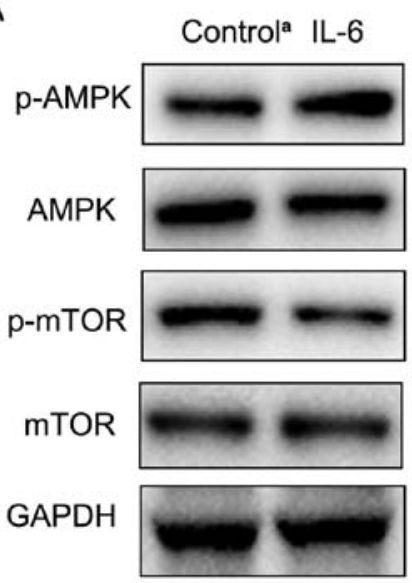

B

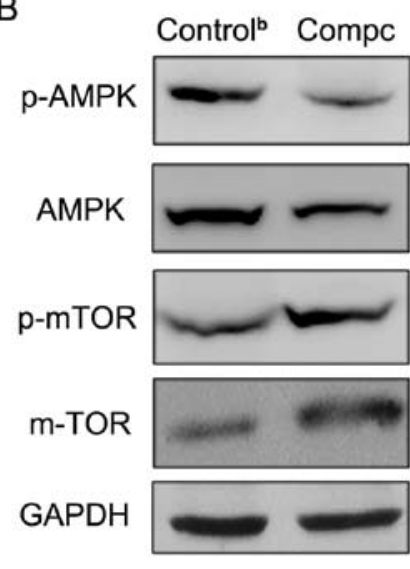

C

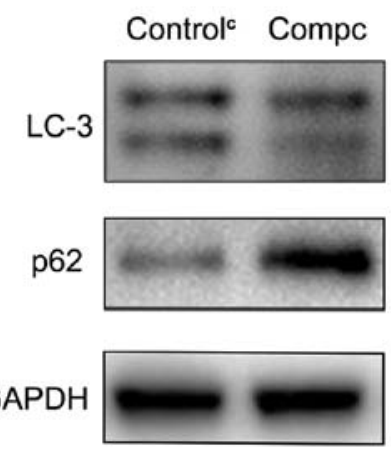

Figure 5. IL-6 activates autophagy by upregulating the AMPK/mTOR signaling pathway. (A) The expression of AMPK, p-AMPK, mTOR and p-mTOR was detected by western blotting in the RBE cell line with treatment of IL-6. (The Control ${ }^{\text {a }}$ group was the RBE cell line without IL- 6 pretreatment). (B) The expression of AMPK, p-AMPK, mTOR and p-mTOR was detected by western blotting in the RBE cell line with treatment of IL-6 and AMPK inhibitor, compound C. (The Control ${ }^{\mathrm{b}}$ group was the RBE cell line without compound C pretreatment). (C) Western blotting was used to examine LC3 and p62 expression in the RBE cell line with treatment of IL-6 and AMPK inhibitor, compound C. (The Control ${ }^{\mathrm{c}}$ group was the RBE cell line with treatment of IL-6 alone). IL-6, interleukin 6; Compc, compound $\mathrm{C}$.

this, a significantly higher rate of cell apoptosis was detected in $\mathrm{RBE}$ cells in the CQ treatment group compared with that in the control group (Fig. 4G-K), thus indicating that apoptosis can be inhibited by autophagy. Therefore, it was established that IL-6 promoted chemoresistance via activating autophagy in cholangiocarcinoma cells.
IL-6 activates autophagy by upregulating the AMPK/mTOR signaling pathway. The present study then investigated the mechanism underlying IL-6-mediated autophagy activation. Previous studies have reported that the AMPK/mTOR signaling pathway mediates cell autophagy activation $(33,34)$, and that activated AMPK negatively regulated mTOR and 
A
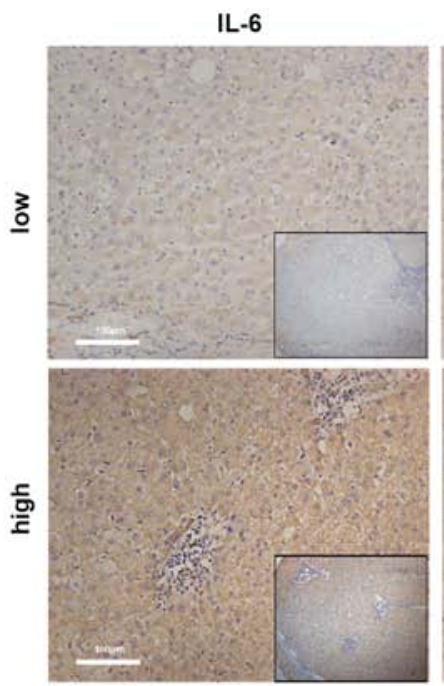

B

C

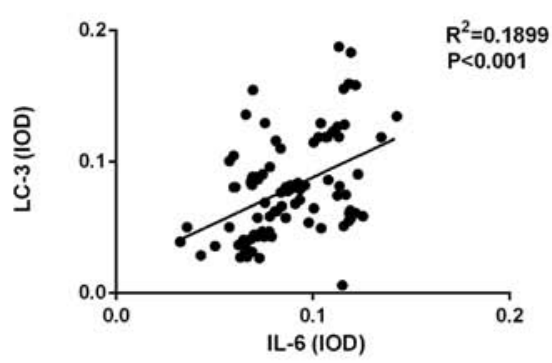

LC-3
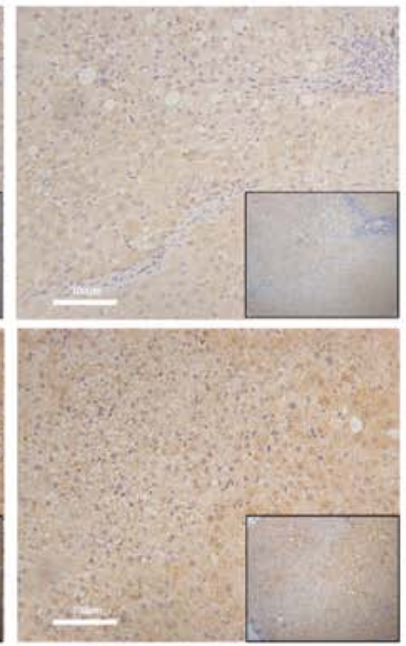

P62
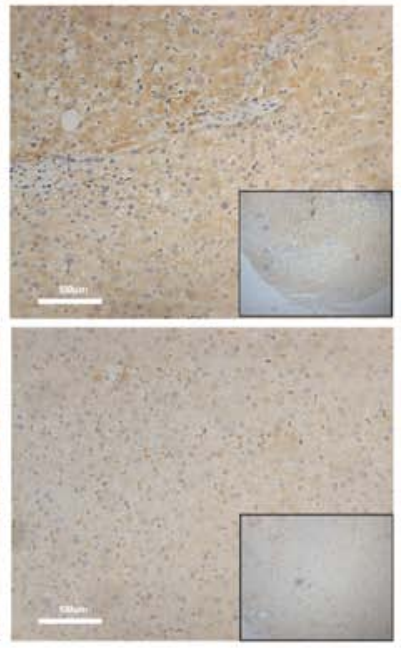

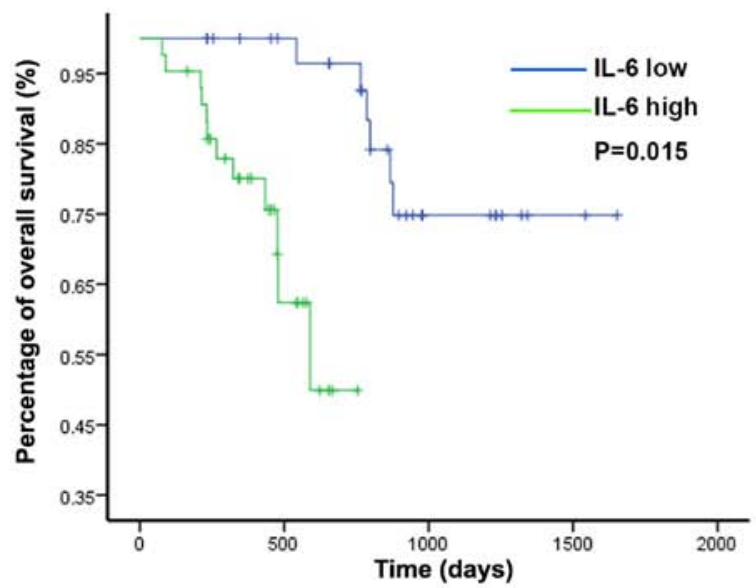

Figure 6. IL-6 level is correlated with autophagy and poor prognosis in clinical specimens of ICC. (A) The expression of IL-6, LC3 and p62 was detected by immunohistochemistry. (B) IOD of LC3 and p62 expression was calculated by IPP analysis following immunohistochemistry in the IL-6-high expression group and IL-6 low-expression group. Then the correlation between the IL-6 level and autophagy-related marker expression was identified. (C) The survival rate of ICC patients was evaluated using the Kaplan-Meier survival analysis. IL-6, interleukin 6; ICC, intrahepatic cholangiocarcinoma; IOD, integrated optical density; IPP, Image-Pro ${ }^{\circledR}$ Plus.

thereby enhanced autophagy flux. Therefore, phosphorylated (p)-AMPK, AMPK, p-mTOR and mTOR levels were detected in cholangiocarcinoma cells following IL-6 treatment using western blotting in the present study. As presented in Fig. 5A, compared with the control group, the level of p-AMPK was increased, while the p-mTOR protein level was decreased in IL-6-disposed RBE cells. Furthermore, to determine the role of the AMPK pathway in IL-6-induced autophagy, the AMPK inhibitor, compound $\mathrm{C}$, was used to suppress AMPK signaling. The western blotting results revealed that compound $\mathrm{C}$ effectively inhibited p-AMPK expression (Fig. 5B). Then, LC3 and p62 expression levels were also detected in RBE cells treated with both IL-6 and compound C. Compared with IL-6-treated alone group, autophagic activity was significantly decreased in both the IL-6 and compound C-treated group (Fig. 5C). These findings indicated that the AMPK/mTOR pathway was involved in IL-6-induced autophagy in cholangiocarcinoma cells.

IL-6 level is associated with autophagy and poor prognosis in clinical specimens of ICC. In order to evaluate the prognostic value of IL-6 in ICC, 80 patients with ICC were 
recruited and tumor tissues were collected. According to the immunohistochemical scoring standard (scores of 0-7 were considered low expression and scores of 8-12 were considered high expression) (24); the patients were divided into two groups: The high-IL-6 level group $(n=44)$ and the low-IL-6 level $(n=36)$ group; It was observed that the expression of LC3 in the high-IL-6 group was increased compared with the low-IL- 6 group and the expression of p62 in the high-IL-6 group was decreased compared with the low-IL-6 group (Fig. 6A). The baseline features between these patients in the two groups were well-balanced (Table I). Furthermore, the integrated optical density (IOD) of LC3 and p62 expression was calculated by IPP analysis following immunohistochemistry in the IL-6-high and IL-6-low expression groups. Then, the association between the expression levels of IL- 6 and autophagy-associated markers was identified. As presented in Fig. 6B, the IL-6 level was significantly associated with LC3 and p62 in ICC tissues. Furthermore, the survival rate of ICC patients was evaluated using the Kaplan-Meier survival analysis. Patients with high IL-6 levels were likely to have significantly poorer survival rate than those with low IL-6 levels (Fig. 6C). The aforementioned results demonstrated that high IL- 6 levels could be a risk factor in the prognosis of patients with HCC.

\section{Discussion}

Chemoresistance is a bottleneck of almost all types of tumor treatments, particularly for those patients who cannot receive surgery. Numerous factors have previously been demonstrated to be associated with chemoresistance, including cancer stem cell survival, multidrug resistance gene activation and protein kinase $C(9,10,35)$. In the present study, it was revealed that MSCs in patients with ICC exhibited high expression levels of HVEM, and HVEM-overexpressing MSCs induced chemoresistance in cholangiocarcinoma cells through production of IL-6, which promoted the activation of autophagy by regulating the AMPK/mTOR signaling pathway.

HVEM is a member of the tumor necrosis factor receptor superfamily and is also a co-stimulatory molecule that mediates the invasion of herpes simplex virus 1 into Chinese hamster ovary cells (36). HVEM is mostly expressed in primary T cells, NK cells, B cells and monocytes, and also in non-immune cells such as hepatocytes, intestinal epithelial cells and smooth muscle cells $(37,38)$. Other studies have demonstrated that HVEM is also expressed on the surface of stromal cells and dendritic cells $(39,40)$. However, to the best of our knowledge, there is currently little research that focuses on the effect of HVEM on MSCs. In the present study, HVEM was revealed to be expressed at a high level in MSCs that were isolated from patients with ICC. Furthermore, HVEM-MSCs could support cholangiocarcinoma cell survival and inhibited apoptosis following treatment with chemotherapy drugs. Further investigation revealed that HVEM could promote IL-6 secretion, which is the key cytokine involved in promoting cholangiocarcinoma cell chemoresistance (41). Previous studies have suggested that the expression level of IL-6 is increased in numerous different types of cancer, including ICC, and serum IL-6 levels are associated with poor prognosis in ICC cases (41-43).
Autophagy is an adaptive response of cells to exogenous stimuli. Autophagy acts as a housekeeping mechanism for cells to maintain a stable state, regulating longevity proteins and renewing peroxide enzymes, mitochondria and the endoplasmic reticulum (44). Autophagy can also act as a defense mechanism to remove damaged organelles and metabolites in the cytoplasm, reconstitute balance of the cytoplasm at the subcellular level, and protect damaged cells (45). In the present study, it was revealed that IL-6 at $10 \mathrm{ng} / \mathrm{ml}$ could effectively promote autophagy and then induce chemotherapy resistance; this concentration of IL- 6 was consistent with other studies (46-48). The present study revealed that, following IL-6 treatment, autophagy was activated and played a key role in the chemoresistance of cholangiocarcinoma cells. It was also demonstrated that the AMPK/mTOR signaling pathway was activated. Autophagy and chemoresistance of cholangiocarcinoma cells induced by IL-6 was weakened when the AMPK/mTOR signaling pathway was blocked. Thus, the AMPK/mTOR signaling pathway contributed to the activation of autophagy. Finally, the present study also verified the association between autophagy and poor prognosis of patients with ICC. Therefore, it can be concluded that MSCs in ICC could overexpress HVEM and secrete high levels of IL-6. Then, IL-6-induced AMPK/mTOR signaling pathway-dependent autophagy supported cholangiocarcinoma cell survival and antitoxic ability. The data attained in the present study can provide new indicators for predicting the prognosis of patients with ICC, and provide potential new targets for treatment.

The present study has some limitations. First, in vitro experiments are insufficient to fully confirm the findings of this study, and it is necessary to further design in vivo experiments to verify the findings. Second, in mesenchymal stem cells, the mechanism of how HVEM induces the increase of IL-6 expression requires further study. Finally, due to the small number of clinical samples included in this study, selection bias may exist in the study design, and the sample size requires further expansion.

\section{Acknowledgements}

Not applicable.

\section{Funding}

The present study was supported by the Foundation of Shanghai Municipal Health Commission (grant no. 2018BR34), the Natural Science Foundation of Shanghai (grant no. 16ZR1400100) and the Medical Guidance Foundation of Shanghai (grant no. 16411966200).

\section{Availability of data and materials}

The datasets used and analyzed during the current study are available from the corresponding author on reasonable request.

\section{Authors' contributions}

LG, HS and XL performed the research, analyzed data, and participated in the writing of the study. ZH, YJ and XY 
analyzed the data and also wrote this study. YX conceived this study, provided funding. MW provided many valuable suggestions and helped the authors to complete the supplementary experiments. All authors read and approved the manuscript and agree to be accountable for all aspects of the research in ensuring that the accuracy or integrity of any part of the work are appropriately investigated and resolved.

\section{Ethics approval and consent to participate}

Ethics approval was obtained from Institutional Ethics Committee of the Eastern Hepatobiliary Surgery Hospital (Shanghai, China), and written informed consent was obtained from each patient.

\section{Patient consent for publication}

Not applicable.

\section{Competing interests}

The authors declare that they have no competing interests.

\section{References}

1. Aljiffry M, Abdulelah A, Walsh M, Peltekian K, Alwayn I and Molinari M: Evidence-based approach to cholangiocarcinoma: A systematic review of the current literature. J Am Coll Surg 208 134-147, 2009.

2. Shaib YH, Davila JA, McGlynn K and El-Serag HB: Rising incidence of intrahepatic cholangiocarcinoma in the United States: A true increase? J Hepatol 40: 472-477, 2004.

3. Florio AA, Ferlay J, Znaor A, Ruggieri D, Alvarez CS, Laversanne M, Bray F, McGlynn KA and Petrick JL: Global trends in intrahepatic and extrahepatic cholangiocarcinoma incidence from 1993 to 2012. Cancer 126: 2666-2678, 2020.

4. Bertuccio P, Malvezzi M, Carioli G, Hashim D, Boffetta P, El-Serag HB, La Vecchia C and Negri E: Global trends in mortality from intrahepatic and extrahepatic cholangiocarcinoma. J Hepatol 71: 104-114, 2019.

5. Roayaie S, Guarrera JV, Ye MQ, Thung SN, Emre S, Fishbein TM, Guy SR, Sheiner PA, Miller CM and Schwartz ME: Aggressive surgical treatment of intrahepatic cholangiocarcinoma: Predictors of outcomes. J Am Coll Surg 187: 365-372, 1998.

6. Endo I, Gonen M, Yopp AC, Dalal KM, Zhou Q, Klimstra D, D'Angelica M, DeMatteo RP, Fong Y, Schwartz L, et al: Intrahepatic cholangiocarcinoma: Rising frequency, improved survival, and determinants of outcome after resection. Ann Surg 248: 84-96, 2008

7. Massani M, Nistri C, Ruffolo C, Bonariol R, Pauletti B, Bonariol L, Caratozzolo E, Morana G and Bassi N: Intrahepatic chemotherapy for unresectable cholangiocarcinoma: Review of literature and personal experience. Updates Surg 67: 389-400, 2015.

8. Bridgewater J, Galle PR, Khan SA, Llovet JM, Park JW, Patel T, Pawlik TM and Gores GJ: Guidelines for the diagnosis and management of intrahepatic cholangiocarcinoma. J Hepatol 60: $1268-1289,2014$.

9. Ho CT, Shang HS, Chang JB, Liu JJ and Liu TZ: Folate deficiency-triggered redox pathways confer drug resistance in hepatocellular carcinoma. Oncotarget 6: 26104-26118, 2015.

10. Zhao LJ, Xu H, Qu JW, Zhao WZ, Zhao YB and Wang JH: Modulation of drug resistance in ovarian cancer cells by inhibition of protein kinase C-alpha (PKC- $\alpha$ ) with small interference RNA (siRNA) agents. Asian Pac J Cancer Prev 13: 3631-3636, 2012.

11. Balko JM, Cook RS, Vaught DB, Kuba MG, Miller TW, Bhola NE, Sanders ME, Granja-Ingram NM, Smith JJ, Meszoely IM, et al: Profiling of residual breast cancers after neoadjuvant chemotherapy identifies DUSP4 deficiency as a mechanism of drug resistance. Nat Med 18: 1052-1059, 2012.
12. Jia Q, Dong Q and Qin L: CCN: Core regulatory proteins in the microenvironment that affect the metastasis of hepatocellular carcinoma? Oncotarget 7: 1203-1214, 2016.

13. Wu SD, Ma YS, Fang Y, Liu LL, Fu D and Shen XZ: Role of the microenvironment in hepatocellular carcinoma development and progression. Cancer Treat Rev 38: 218-225, 2012.

14. Hinshaw DC and Shevde LA: The tumor microenvironment innately modulates cancer progression. Cancer Res 79: 4557-4566, 2019

15. Uchibori R, Tsukahara T, Mizuguchi H, Saga Y, Urabe M, Mizukami H, Kume A and Ozawa K: NF- $\mathrm{KB}$ activity regulates mesenchymal stem cell accumulation at tumor sites. Cancer Res 73: 364-372, 2013.

16. Ljujic B, Milovanovic M, Volarevic V, Murray B, Bugarski D, Przyborski S, Arsenijevic N, Lukic ML and Stojkovic M: Human mesenchymal stem cells creating an immunosuppressive environment and promote breast cancer in mice. Sci Rep 3: 2298, 2013.

17. Kim JA, Shim JS, Lee GY, Yim HW, Kim TM, Kim M, Leem SH, Lee JW, Min CK and Oh IH: Microenvironmental remodeling as a parameter and prognostic factor of heterogeneous leukemogenesis in acute myelogenous leukemia. Cancer Res 75: 2222-2231, 2015.

18. He W, Liang B, Wang C, Li S, Zhao Y, Huang Q, Liu Z, Yao Z, Wu Q, Liao W, et al: MSC-regulated IncRNA MACC1-AS1 promotes stemness and chemoresistance through fatty acid oxidation in gastric cancer. Oncogene 38: 4637-4654, 2019.

19. Gu ZW, He YF, Wang WJ, Tian Q and Di W: miR-1180 from bone marrow-derived mesenchymal stem cells induces glycolysis and chemoresistance in ovarian cancer cells by upregulating the Wnt signaling pathway. J Zhejiang Univ Sci B 20: 219-237, 2019.

20. Han Z, Jing Y, Xia Y, Zhang S, Hou J, Meng Y, Yu F, Liu X, Wu M, Zhang P, et al: Mesenchymal stem cells contribute to the chemoresistance of hepatocellular carcinoma cells in inflammatory environment by inducing autophagy. Cell Biosci 4: 22, 2014.

21. Haga H, Yan IK, Takahashi K, Wood J, Zubair A and Patel T: Tumour cell-derived extracellular vesicles interact with mesenchymal stem cells to modulate the microenvironment and enhance cholangiocarcinoma growth. J Extracell Vesicles 4: $24900,2015$.

22. Liu J, Han G, Liu H and Qin C: Suppression of cholangiocarcinoma cell growth by human umbilical cord mesenchymal stem cells: A possible role of Wnt and Akt signaling. PLoS One 8: e62844, 2013

23. Livak KJ and Schmittgen TD: Analysis of relative gene expression data using real-time quantitative PCR and the 2(-Delta Delta C(T)) Method. Methods 25: 402-408, 2001.

24. Konno R, Yamakawa H, Utsunomiya H, Ito K, Sato $S$ and Yajima A: Expression of survivin and Bcl-2 in the normal human endometrium. Mol Hum Reprod 6: 529-534, 2000.

25. Gang EJ, Bosnakovski D, Figueiredo CA, Visser JW and Perlingeiro RC: SSEA-4 identifies mesenchymal stem cells from bone marrow. Blood 109: 1743-1751, 2007.

26. Rasini V, Dominici M, Kluba T, Siegel G, Lusenti G, Northoff H, Horwitz EM and Schäfer R: Mesenchymal stromal/stem cells markers in the human bone marrow. Cytotherapy 15: 292-306, 2013.

27. Tang Q, Wang Q, Zhang Q, Lin SY, Zhu Y, Yang X and Guo AY: Gene expression, regulation of DEN and HBx induced HCC mice models and comparisons of tumor, para-tumor and normal tissues. BMC Cancer 17: 862, 2017.

28. Critelli R, Milosa F, Faillaci F, Condello R, Turola E, Marzi L, Lei B, Dituri F, Andreani S, Sighinolfi P, et al: Microenvironment inflammatory infiltrate drives growth speed and outcome of hepatocellular carcinoma: A prospective clinical study. Cell Death Dis 8: e3017, 2017.

29. Alshareeda AT, Sakaguchi K, Abumaree M, Mohd Zin NK, Shimizu T and Zoran IJPO: The potential of cell sheet technique on the development of hepatocellular carcinoma in rat models. PLoS One 12: e0184004, 2017.

30. Jiang S, Chang H, Deng S and Fan D: Icariin enhances the chemosensitivity of cisplatin resistant ovarian cancer cells by suppressing autophagy via activation of the AKT/mTOR/ATG5 pathway. Int J Oncol 54: 1933-1942, 2019.

31. Huang S,QiP,ZhangT,LiFandHeX:TheHIF-1 $\alpha /$ miR-224-3p/ATG5 axis affects cell mobility and chemosensitivity by regulating hypoxia induced protective autophagy in glioblastoma and astrocytoma. Oncol Rep 41: 1759-1768, 2019.

32. White E, Mehnert JM and Chan CS: Autophagy, Metabolism, and Cancer. Clin Cancer Res 21: 5037-5046, 2015. 
33. He J, Ding J, Lai Q, Wang X, Li A and Liu S: Irbesartan ameliorates lipid deposition by enhancing autophagy via PKC/AMPK/ULK1 axis in free fatty acid induced hepatocytes. Front Physiol 10: 681, 2019.

34. Chen X, Li C, Chen Y, Ni C, Chen X, Zhang L, Xu X, Chen M, Ma X, Zhan H, et al: Aflatoxin B1 impairs leydig cells through inhibiting AMPK/mTOR-mediated autophagy flux pathway. Chemosphere 233: 261-272, 2019.

35. Zhang J, Yuan B, Zhang H and Li H: Human epithelial ovarian cancer cells expressing CD105, CD44 and CD106 surface markers exhibit increased invasive capacity and drug resistance. Oncol Lett 17: 5351-5360, 2019.

36. Nicola AV, Ponce de Leon M, Xu R, Hou W, Whitbeck JC, Krummenacher C, Montgomery RI, Spear PG, Eisenberg RJ and Cohen GH: Monoclonal antibodies to distinct sites on herpes simplex virus (HSV) glycoprotein D block HSV binding to HVEM. J Virol 72: 3595-3601, 1998.

37. Wahl C, Wegenka UM, Leithäuser F, Schirmbeck R and Reimann J: IL-22-dependent attenuation of T cell-dependent (ConA) hepatitis in herpes virus entry mediator deficiency. J Immunol 182: 4521-4528, 2009.

38. Xu H, Cao D, Guo G, Ruan Z, Wu Y and Chen Y: The intrahepatic expression and distribution of BTLA and its ligand HVEM in patients with HBV-related acute-on-chronic liver failure. Diagn Pathol 7: 142, 2012.

39. $\mathrm{Yu} \mathrm{P}$ and Fu YX: Targeting tumors with LIGHT to generate metastasis-clearing immunity. Cytokine Growth Factor Rev 19: 285-294, 2008.

40. Klionsky DJ and Ohsumi Y: Vacuolar import of proteins and organelles from the cytoplasm. Annu Rev Cell Dev Biol 15: 1-32, 1999.
41. Isomoto H, Mott JL, Kobayashi S, Werneburg NW, Bronk SF, Haan S and Gores GJ: Sustained IL-6/STAT-3 signaling in cholangiocarcinoma cells due to SOCS-3 epigenetic silencing. Gastroenterology 132: 384-396, 2007.

42. Meng F, Yamagiwa Y, Ueno Y and Patel T: Over-expression of interleukin-6 enhances cell survival and transformed cell growth in human malignant cholangiocytes. J Hepatol 44: 1055-1065, 2006.

43. Asukai K, Kawamoto K, Eguchi H, Konno M, Nishida N, Koseki J, Noguchi K, Hasegawa S, Ogawa H, Yamada D, et al: Prognostic impact of peritumoral IL-17-positive cells and IL-17 axis in patients with intrahepatic cholangiocarcinoma. Ann Surg Oncol 22 (Suppl 3): S1524-S1531, 2015.

44. Burman C and Ktistakis NT: Autophagosome formation in mammalian cells. Semin Immunopathol 32: 397-413, 2010.

45. Komatsu M and Ichimura Y: Selective autophagy regulates various cellular functions. Genes Cells 15: 923-933, 2010.

46. Pei X, Li Y, Zhu L and Zhou Z: Astrocyte-derived exosomes suppress autophagy and ameliorate neuronal damage in experimental ischemic stroke. Exp Cell Res 382: 111474, 2019.

47. Shi W, Ma H, Liu T, Yan D, Luo P, Zhai M, Tao J, Huo S, Guo J, Li C, et al: Inhibition of Interleukin-6/glycoprotein 130 signalling by Bazedoxifene ameliorates cardiac remodelling in pressure overload mice. J Cell Mol Med 24: 4748-4761, 2020.

48. Lu H, Han M, Yuan X, Tursun K, Zhang Y, Li Y, Li Z, Feng S, Zhou L, Pan Z, et al: Role of IL-6-mediated expression of NS5ATP9 in autophagy of liver cancer cells. J Cell Physiol 233: 9312-9319, 2018.

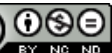

This work is licensed under a Creative Commons Attribution-NonCommercial-NoDerivatives 4.0 International (CC BY-NC-ND 4.0) License. 